\title{
Variations in life expectancy between rural and urban areas of England, 2001-07
}

Lynsey Kyte and Claudia Wells Office for National Statistics

\section{Abstract}

\section{Background}

This study was part of a wider project commissioned by the Department for Environment, Food and Rural Affairs (Defra) to examine inequalities in health outcomes in rural areas. It investigated variations in life expectancy at birth between rural and urban areas of England, taking the effect of deprivation into account. The study aimed to produce results which provide specific evidence of the needs of rural communities, as they have often been overlooked in previous research.

\section{Methods}

The Rural and Urban Area Classification (RUAC) 2004 and the Index of Multiple Deprivation (IMD) 2007 were used to categorise area types at the Lower Super Output Area (LSOA) level. Population and mortality data used were produced by the Office for National Statistics (ONS). Abridged life tables were constructed to calculate period life expectancy at birth for males and females, for the years 2001 to 2007 combined. Confidence intervals (95\%) were also produced.

\section{Results}

For the 2001-07 period, life expectancy at birth in England was 76.9 years for males and 81.3 years for females. However, when deprivation was examined, results between the most deprived and least deprived quintiles varied by 7.8 years for men and 5.4 years for women.

Overall, life expectancy was higher in rural areas than in urban areas. Deprivation had a considerable impact on the results and wide inequalities were evident, particularly in men and in urban areas. In both area types, males living in the less deprived quintiles had similar life expectancies to females living in the more deprived quintiles.

Within rural area types, life expectancy was higher in village and dispersed settlements than in town and fringe areas. There were large differences between the fourth and fifth (most deprived) quintiles in village and dispersed settlements, which shows that there may be acute pockets of deprivation within this area type that need to be addressed. 
In terms of sparsity, there was little difference in life expectancy between densely and less densely populated localities within rural and urban areas. However, variations were observed when deprivation was taken into account and greater differences were evident in less sparse areas than in sparse areas.

\section{Conclusions}

There were clear inequalities in life expectancy between rural and urban areas in England. There were also intricate differences within area types, which can be overlooked when only examining differences between them. The results were consistent with the findings of previous studies and demonstrated that it is important to examine differences in life expectancy in both area and deprivation contexts. 


\section{Contents}

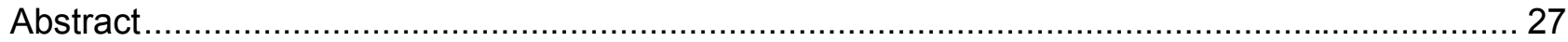

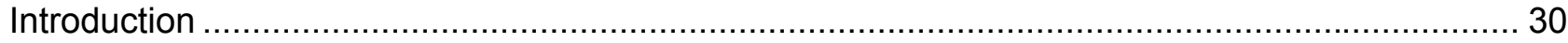

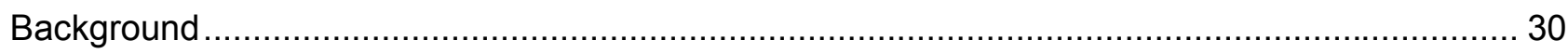

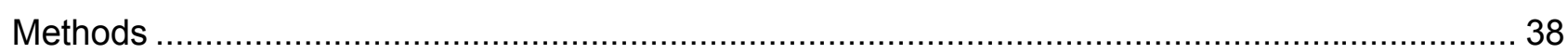

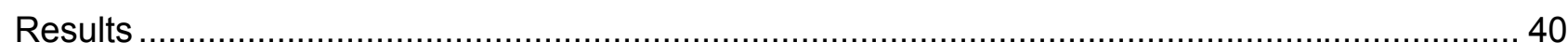

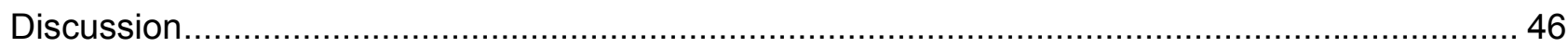

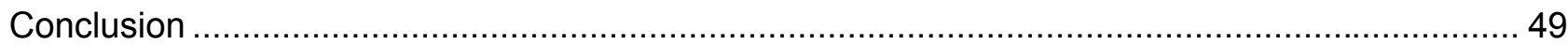

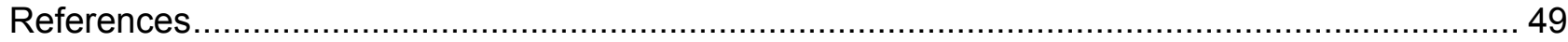

\section{List of Tables}

Table 1 Number of LSOAs in England by RUAC 2004 and IMD 2007 quintile, 2001-07........38

Table 2 Period life expectancy at birth by sex and rural/urban settlement type of the RUAC 2004 and IMD 2007 quintile, England, 2001-07.

Table 3 Period life expectancy at birth by sex and rural/urban sparsity context of the RUAC 2004 and IMD 2007 quintile, England, 2001-07.

\section{List of Figures}

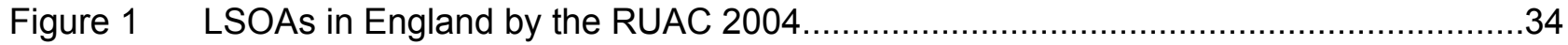

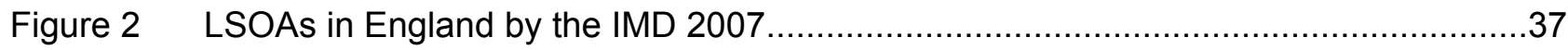

Figure 3 Period life expectancy at birth by sex and rural/urban dichotomy of the RUAC 2004 and IMD 2007 quintile, England, 2001-07.

Figure 4 Period life expectancy at birth by sex and settlement type of the RUAC 2004, England,

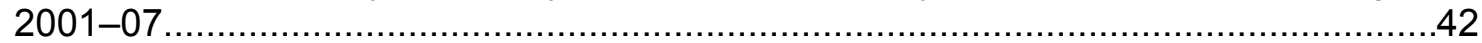

Figure 5 Period life expectancy at birth by sex and rural/urban settlement type of the RUAC 2004 and IMD 2007 quintile, England, 2001-07.

Figure 6 Period life expectancy at birth by sex and rural/urban sparsity context of the RUAC 2004, England, 2001-07. 


\section{Introduction}

This study was part of a project commissioned by the Department for Environment, Food and Rural Affairs (Defra) to investigate inequalities in health outcomes in rural areas of England. Past research into geographical health inequalities in the UK has often focused on variations between administrative areas, sometimes incorporating measures of socio-economic circumstances. There has been relatively little analysis into health inequalities between rural and urban areas, or particularly within rural areas.

The main aim of this project was to examine health advantages and disadvantages in different types of rural areas. This was done by investigating a number of health indicators (including access to services, mortality and life expectancy) to produce results which provide evidence of the needs of rural communities, which can then be addressed through public policy and delivery.

This particular study investigated differences in period life expectancy at birth in England according to different rural and urban area types within the Rural and Urban Area Classification (RUAC) 2004. The effect of deprivation within each area, measured using the Index of Multiple Deprivation (IMD) 2007, was also examined. The analyses utilised the latest population and mortality data, aggregated over the 2001-07 period, to provide a more detailed and robust examination of variations in life expectancy between rural and urban areas than has been produced previously.

\section{Background}

There is a common notion of a 'rural idyll' and associated beliefs that rural populations are healthier than their urban counterparts. Various environmental, social and economic factors are often thought to contribute to better rural health. For instance, the availability of clean air, green space and the opportunity for healthy exercise is widely considered to have significant health advantages. Rural areas also experience less deprivation and there is increasing evidence of gentrification (whereby better-off people migrate to the countryside and displace those who are less affluent) in rural settlements (Commission for Rural Communities 2008; Joseph Rowntree Foundation 2000). However, these observations may mask important differences within rural areas, which mean that inequalities are sometimes hidden by favourable averages (Haynes and Gayle 2000).

Rural populations tend to be older than those in urban areas. Ageing is strongly associated with greater healthcare needs, although it has been suggested that rural communities receive relatively less funding than urban areas, meaning that rural health needs may go unmet (Commission for Rural Communities 2008). Rural dwellers are also affected by issues such as the centralisation of services in urban localities, meaning that access to health and social care services can be compromised at key stages for those living in rural areas. Suppositions that people in rural areas experience better health advantages are therefore frequently challenged (Asthana et al. 2002).

\section{Life expectancy}

Life expectancy at birth has been used as a measure of the health status of the population in England and Wales since the 1840s, and was employed in some of the earliest reports of the 
Registrar General to illustrate the differences in mortality experienced by populations in different parts of the country (Toson and Baker 2003).

At present, the Office for National Statistics (ONS) reports annually on life expectancy figures for the United Kingdom (UK), constituent countries and sub-national areas down to local authority level. Results are calculated as three-year averages in accordance with methodological recommendations (Toson and Baker 2003). Life expectancy at birth in the UK is generally higher for females than males and is higher in the south compared with the north (Kyte and Gordon 2009; Office for National Statistics 2009a). For 2006-08, life expectancy in England was highest in the South East, South West and East of England and lowest in the North West and North East. At local authority level, broad inequalities were evident and figures ranged from 73.6 years to 84.3 years for males and from 78.8 years to 88.9 years for females.

In addition to the standard annual figures, results have also been periodically produced to examine life expectancy within smaller geographical areas. ONS calculated life expectancy at ward-level in England and Wales as experimental statistics for the 1999-03 period, aiming to identify a suitable methodology for use with small populations, to establish a minimum population size to make the calculations feasible, and to consider the effects of having no deaths in some age groups (Toson and Baker 2003). The study explored various methods and concluded that Chiang's revised methodology should be used for all sub-national life expectancy calculations, calculations should not be performed for areas with populations of less than 5,000 , and that if there are no deaths in the final age band, a value based on national age-specific death rates should be inserted. These recommendations have been followed in this study to calculate life expectancy for rural and urban areas.

While the annual figures provide a useful indicator of health outcomes and are used for monitoring changes and variations in the population's life expectancy, it is not possible to assess specific rural and urban community needs using the results because these areas are not neatly distributed within administrative geographical areas.

At present, there are relatively few studies that have focused on variations in life expectancy between and within rural and urban areas of England and in areas with different levels of deprivation (Charlton 1996; Raleigh and Kiri 1997; Woods et al. 2005; Gartner et al. 2007). On the whole, they have reported that life expectancies are higher in rural and less deprived areas and lower in urban and more deprived areas, regardless of the time period under investigation. However, the studies are based on differing area and deprivation classifications and the results are now dated. This study develops previous work by using the government's current area and deprivation classifications, and the latest population and mortality data to present a detailed and robust analysis of variations in life expectancy between rural and urban areas in England.

\section{Rural and urban}

There are numerous definitions and conceptualisations in the literature of what constitutes rural and urban. The way in which these concepts are defined and understood influences the methods and findings of research (Higgs 1999). For statistical and analytical purposes various classifications have been developed in past research to categorise urban and rural areas. For example, Haynes and Gayle (2000) constructed four urban and rural typologies based on ward 
population sizes and distance to a district general hospital. In another example, Huff et al. (1999) developed a classification based on the grouping of enumeration districts into urban areas and their subsequent total population sizes. However, such classifications are often devised for individual studies and are therefore limited in the extent to which they can be compared. Further, they are often biased towards urban areas (Barnett et al. 2002).

Official classifications of rural and urban areas have been periodically produced by UK government departments. The Rural and Urban Area Classification 2004 for England and Wales was sponsored and developed by various agencies (including Defra, ONS and The Countryside Agency) to overcome the weaknesses identified in previous rural and urban definitions. In particular, rural definitions based on socio-economic circumstances were regarded as unsuitable (The Countryside Agency et al. 2004).

In the RUAC, areas with a population of 10,000 or more were categorised as urban, whereas rural settlements were identified according to household and residential land use and densities (Bibby and Shepherd 2004). Areas were then defined according to settlement types and context (sparsity). The classes 'sparse' and 'less sparse' can be interpreted as 'less densely populated' and 'densely populated' respectively. The smallest geography which areas were classified at was 2001 Census Output Areas, which can then be aggregated to larger geographies. Output area boundaries remained stable over the 2001-07 period. Based on sparsity and settlement types, a two-tiered classification can then be structured for rural areas. Box 1 shows the urban and rural classes used in this study.

\section{Box 1 Rural and Urban Area Classification 2004}

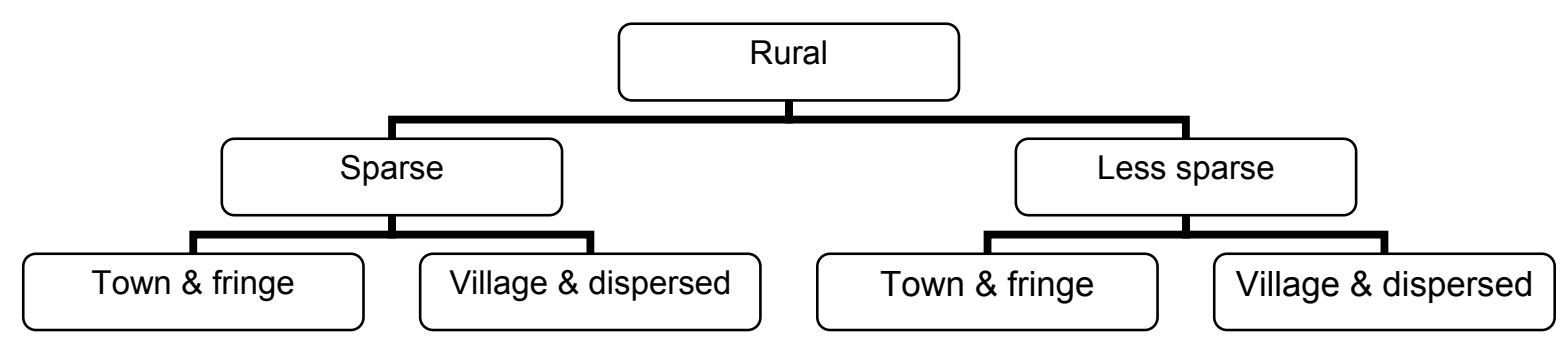

Source: Adapted from Bibby and Shepherd (2004) 
The RUAC is a detailed and flexible classification that enables statistical analyses to be performed for a simple rural/urban dichotomy, sparse and less sparse areas, different settlement types, or for the individual classes, depending on the level of analysis required. It improves previous classifications by incorporating a strong rural element and enables more sophisticated analyses to be conduced within rural areas than has arguably been previously possible. As the national standard measure, the use of the RUAC allows statistical indicators to be compared across different topical areas.

A map of England illustrating the RUAC at the Lower Super Output Area (LSOA) level is displayed in Figure 1. The map shows that densely populated urban areas are concentrated in and around London, Greater Manchester, Merseyside, and Tyne and Wear. There are also large urban concentrations within Yorkshire and the Humber and the Midlands. In contrast, sparse village and dispersed areas are mainly located in the North of England, particularly around Cumbria. There are also rural pockets on the east coast, in the south east, and in the west of the country.

Approximately 80 per cent of the population lived in urban areas and 20 per cent lived in rural areas during the 2001-07 period. 
Figure $1 \quad$ LSOAs in England by the RUAC 2004

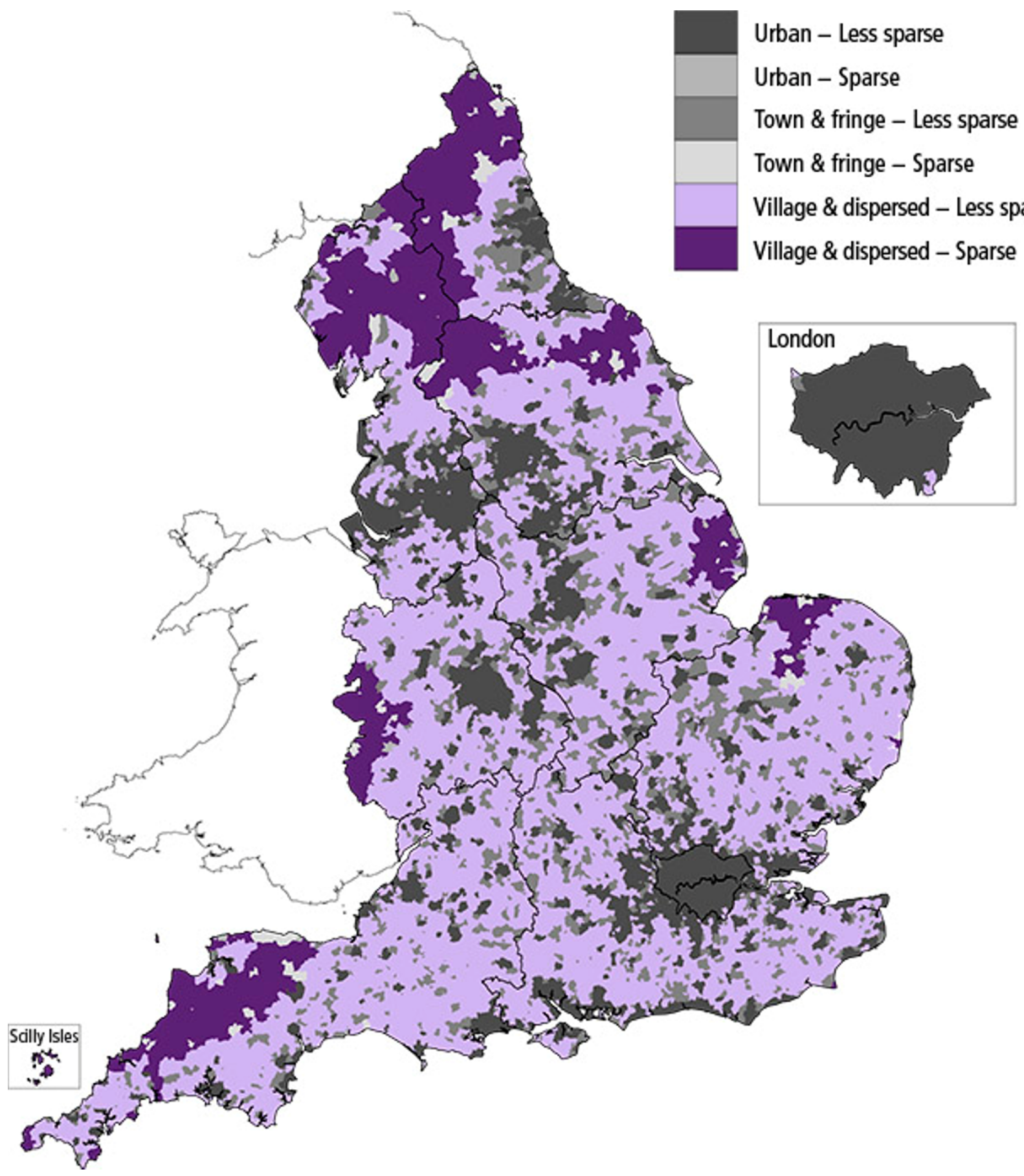

\section{Deprivation}

To understand health variations between rural and urban areas further, analyses of deprivation permit a more in-depth exploration of inequalities within specific area types, which may be hidden by favourable averages of health (Haynes and Gale 2000). Like the concepts of rural and urban, deprivation has been defined and measured in a variety of ways. The term is often used interchangeably with others such as disadvantage, inequality, poverty and social exclusion (Asthana et al. 2002). Broadly, there are two types of deprivation: economic and social, which manifest through numerous indicators such as income, education and health. 
Several indices have been developed and employed in previous studies to quantify indicators of deprivation (for example Jarman 1983; Townsend et al. 1988; Carstairs and Morris 1989). However, they have been widely criticised for having an urban bias, meaning that rural issues have often been overlooked, which has potential implications for resource allocation and service planning (Martin et al. 2000). Perhaps the most notable criticism levelled against the Townsend and Carstairs-Morris indices concerns the car-ownership indicator. It is argued that rural residents are more reliant on cars than urban dwellers (Gilthorpe and Wilson 2003). Although car-ownership may be a good indicator of wealth in cities, high levels of ownership in rural areas may misrepresent the socio-economic conditions because it is often due to a lack of public transport provision rather than wealth (Haynes and Gale 2000).

The Index of Multiple Deprivation was introduced in 2000. The car-ownership variable was excluded as a deprivation measure, mainly due to criticisms like those above. Uniquely, it included geographical access to services as a measure of deprivation, which is an element that was previously overlooked (Jordan et al. 2004). The more recent IMD 2004 and IMD 2007 contain an additional domain of crime. The IMD 2007, used in this study, brings together 38 different indicators which fall within seven domains. The domains each have an associated weight and they are combined to create the overall deprivation index. The domains and weights are shown in Box 2.

\section{Box 2 Index of Multiple Deprivation 2007}

\begin{tabular}{lr}
\hline Domain & Domain weight \\
\hline Income deprivation & $22.5 \%$ \\
Employment deprivation & $22.5 \%$ \\
Health deprivation and disability & $13.5 \%$ \\
Education, skills and training deprivation & $13.5 \%$ \\
Barriers to housing and services & $9.3 \%$ \\
Crime & $9.3 \%$ \\
Living environment deprivation & $9.3 \%$ \\
\hline
\end{tabular}

Source: Communities and Local Government (2008)

The IMD has been used in various studies to report differences in health outcomes, generally finding better health in the least deprived areas and worse health in the most deprived. For instance, the IMD 2004 was used in a study to determine whether differences between rural and urban mortality were evident once deprivation was taken into account (Gartner et al. 2008). When adjustments for deprivation were made in a logistic regression analysis, it was found that differences in mortality were significantly reduced in males, but less so in females. Gartner also investigated the impact of deprivation on mortality rates by including and excluding the health domain, using the income domain only, and using the Townsend index, finding little effect on the 
overall results (unpublished). Such studies demonstrate the importance of incorporating deprivation measures when examining differences between rural and urban areas.

A map of England illustrating the IMD 2007 at LSOA level is displayed in Figure 2. It shows that the least deprived areas are mainly located in the southern and eastern regions, while the most deprived areas are located in and around urban concentrations (as shown in Figure 1). There are also a lot of deprived localities in eastern and southern coastal areas, which are often associated with older and seachange populations.

Based on the IMD 2007, the Commission for Rural Communities (2008) state that, on average, rural areas have less concentrated deprivation than urban areas. In terms of sparsity, they observe that levels of deprivation within sparse towns and villages are similar to the levels of deprivation experienced in urban areas. Areas with the least deprivation are identified in 'commuter belt' areas and in the centre of the South of England, where income levels are highest (Commission for Rural Communities 2008). 
Figure 2 LSOAs in England by the IMD 2007

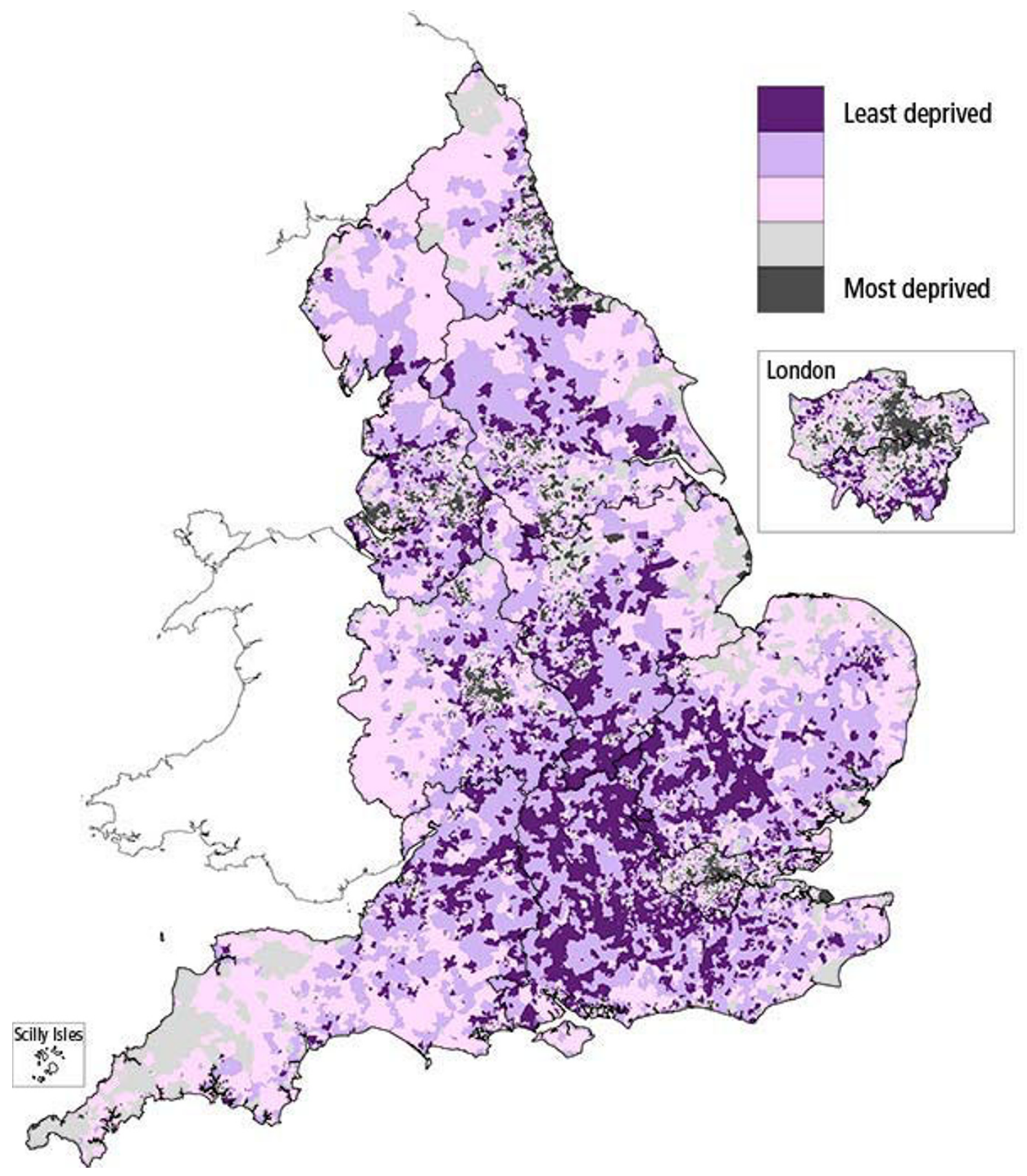




\section{Methods}

\section{Rural and Urban Area Classification (RUAC) 2004}

The RUAC 2004 was used in this study to classify areas in England at the LSOA level. There are 32,482 LSOAs in England, with an average population of 1,500 people. Using this classification, results were produced for England, the rural/urban dichotomy, settlement types and sparsity contexts.

\section{Index of Multiple Deprivation (IMD) 2007}

The IMD 2007 was additionally employed in this study to assess the impact of deprivation on life expectancies within rural and urban areas. Based on this Index, each LSOA has a total deprivation score and is ranked from 1 (least deprived) to 32,482 (most deprived). The LSOAs were split into approximately equal quintiles for analysis in this study.

Table 1 shows the number of LSOAs in each deprivation quintile according to the six classes of the RUAC. For rural areas, there are more LSOAs in the least deprived quintiles and fewer in the most deprived areas. The urban LSOAs are distributed more evenly across the deprivation quintiles.

\section{Table $1 \quad$ Number of LSOAs in England by RUAC 2004 and IMD 2007 quintile, 2001-07}

\begin{tabular}{|c|c|c|c|c|c|c|c|c|}
\hline \multicolumn{4}{|c|}{ RUAC 2004} & \multicolumn{3}{|c|}{ IMD 2007} & \multirow[b]{2}{*}{ Most } & \multirow[b]{2}{*}{ Total } \\
\hline Dichotomy & Context & Settlement & Least & 2 & 3 & 4 & & \\
\hline \multirow[t]{2}{*}{ Urban } & Sparse & $\geq 10,000$ population & 2 & 12 & 18 & 27 & 11 & 70 \\
\hline & Less sparse & $\geq 10,000$ population & 4,704 & 4,471 & 4,996 & 5,873 & 6,341 & 26,385 \\
\hline \multirow[t]{4}{*}{ Rural } & Sparse & Town \& fringe & 17 & 40 & 56 & 38 & 1 & 152 \\
\hline & & Village \& dispersed & 5 & 36 & 128 & 57 & 1 & 227 \\
\hline & Less Sparse & Town \& fringe & 1,118 & 799 & 571 & 317 & 124 & 2,929 \\
\hline & & Village \& dispersed & 652 & 1,139 & 727 & 184 & 17 & 2,719 \\
\hline Total & & & 6,498 & 6,497 & 6,496 & 6,496 & 6,495 & 32,482 \\
\hline
\end{tabular}

These categories have small populations and were therefore excluded from the sparsity context life expectancy calculations.

Life expectancy figures were calculated by IMD 2007 quintiles for each of the RUAC groups outlined above. However, two categories (least deprived urban sparse areas and most deprived rural sparse areas) were excluded from the calculations for methodological reasons because they have small populations (Toson and Baker 2003).

\section{Populations and mortality data}

The population data used were unpublished, experimental mid-year LSOA population estimates split by sex and five-year age group, produced by ONS. ONS mortality data for persons whose 
usual place of residence was in England, by sex and five-year age group were also used. The data were combined for the years 2001 to 2007 to ensure that the numbers were large enough, particularly in areas with fewer LSOAs, to ensure that the results calculated were sufficiently robust.

\section{Calculation of period life expectancy}

Abridged life tables were constructed using standard methods (Newell 1994; Shyrock and Siegel 1976). Separate tables were constructed for males and females, and for each analysis with and without the inclusion of IMD 2007 quintiles. The tables were created using annual mid-year population estimates and numbers of deaths registered in each calendar year, which were aggregated over the 2001-07 period. A detailed description of the standard methods and notation associated with the calculation of life expectancy can be found on the Government Actuary's Department website (Government Actuary's Department, online a, online b).

Confidence intervals were calculated using the method developed by Chiang (1968). A report detailing research undertaken by ONS to compare methodologies to allow the calculation of confidence intervals for life expectancy at birth has been published in the National Statistics Methodology Series (Toson and Baker 2003). Confidence intervals are a measure of the statistical precision of an estimate and show the range of uncertainty around the estimated figure.

Calculations based on small numbers of events, as is the case in some areas in this analysis, are often subject to random fluctuations. As a general rule, if the confidence interval around one figure overlaps with the interval around another, we cannot say with certainty that there is more than a chance difference between the two figures. Confidence intervals are represented by error bars on the charts below.

An example of a life table constructed using the same method used to calculate life expectancy and confidence intervals in this article can be found on the ONS website (Office for National Statistics 2005).

\section{Interpretation of results}

All figures presented are period life expectancies. Period expectation of life at a given age for an area in a given time period is an estimate of the average number of years a person of that age would survive if he or she experienced the particular area's age-specific mortality rates for that time period throughout the rest of his or her life. The figures reflect mortality among those living in the area in each time period, rather than mortality among those born in each area. It is not therefore the number of years a person in the area in each time period could actually expect to live, both because the death rates of the area are likely to change in the future and because many of those in the area may live elsewhere for at least some part of their lives.

Period life expectancy at birth is also not a guide to the remaining expectation of life at any given age. For example, if female life expectancy was 80 years for a particular area, the life expectancy of women aged 65 years in that area would exceed 15 years. This reflects the fact that survival from a particular age depends only on the mortality rates beyond that age, whereas survival from birth is based on mortality rates at every age. 


\section{Results}

\section{Life expectancy in rural and urban areas}

For 2001-07, life expectancy at birth for males in England was 76.9 years. For females, life expectancy was 4.4 years higher at 81.3 years. However, when the figures were calculated by IMD 2007 quintiles, wide variations were observed. Life expectancy for males ranged from 72.4 years in the most deprived areas to 80.2 years in the least deprived areas. For females, expectation of life varied from 78.1 years in the most deprived to 83.5 years in the least deprived areas. This showed differences of 7.8 years and 5.4 years respectively, indicating broader inequalities among males than females.

Using the RUAC 2004, England was divided into dichotomous rural and urban areas. Life expectancy was higher in rural areas than in urban areas for both males and females. For men, life expectancy was 78.6 years in rural areas and 76.5 years in urban areas. The respective figures for women were 82.4 years and 81.0 years. The difference in life expectancy between the areas was wider among males (2.1 years) than females (1.4 years).

When deprivation quintiles were included in the calculations, more detailed differences in life expectancy were evident. Figure 3 shows that in the least deprived quintile, the life expectancy of both males and females was slightly higher in urban areas than in the least deprived rural areas. However, in the other quintiles, life expectancy was lower in urban areas for both men and women. Although the differences between rural and urban areas were relatively small, the gaps in life expectancy tended to be wider between the more deprived quintiles, particularly in males.

In males, life expectancy in urban areas ranged from 72.3 years in the most deprived quintile to 80.3 years in the least deprived, compared with 73.5 years and 79.9 years respectively in rural areas. The variations were much smaller in females, with life expectancy ranging from 78.1 years to 83.6 years in the most deprived to the least deprived urban areas and from 78.4 years to 83.3 years respectively in rural areas. The figures show that inequalities were widest among men in urban areas (8.0 years). 
Figure 3 Period life expectancy at birth by sex and rural/urban dichotomy of the RUAC 2004 and IMD 2007 quintile, England, 2001-07

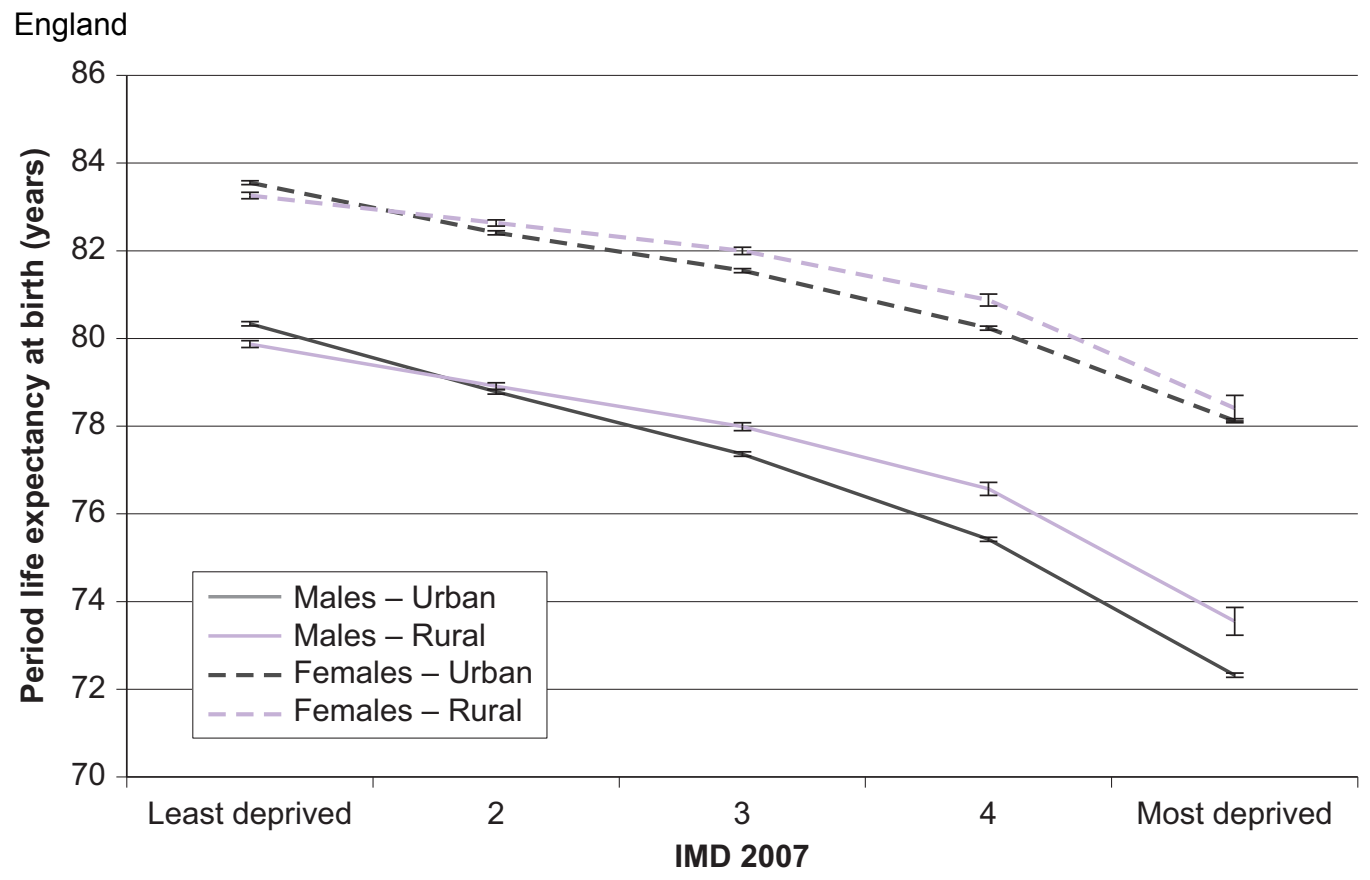

Life expectancy in rural and urban settlement types

To provide further detail of variations within rural areas, life expectancy was calculated by the three settlement types of the RUAC 2004: urban, town and fringe, and village and dispersed areas. Figure 4 shows that the expectation of life for males and females was highest in village and dispersed areas and lowest in urban areas. 


\section{Figure $4 \quad$ Period life expectancy at birth by sex and settlement type of the RUAC 2004, England, 2001-07}

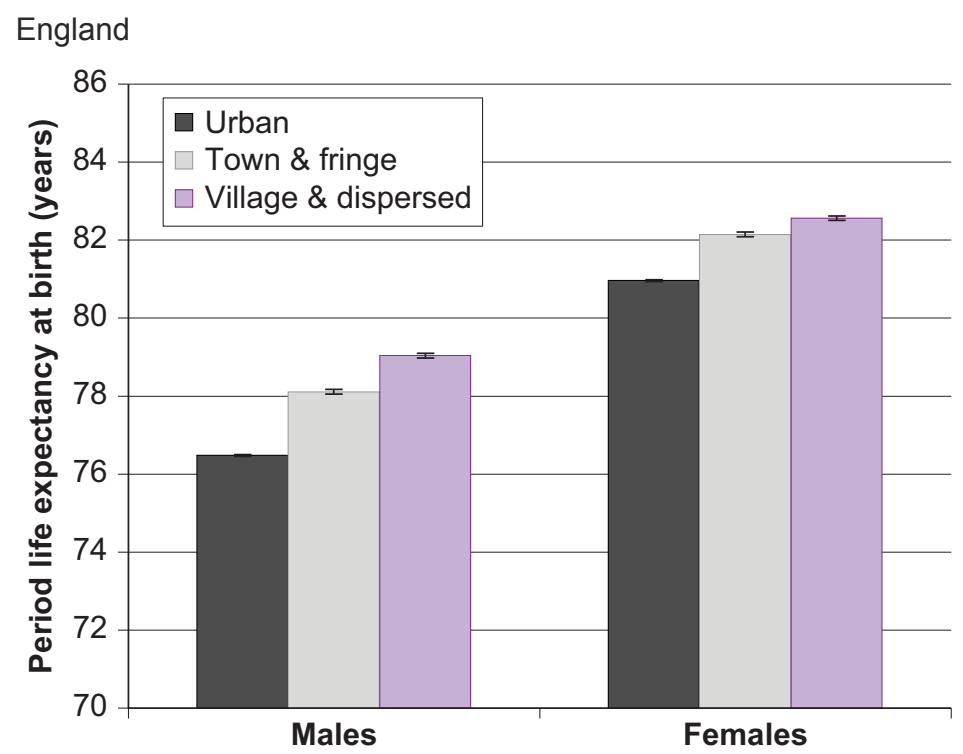

When deprivation quintiles were included in the calculations, Table 2 shows that the life expectancy of males was highest in the least deprived urban areas. However, it was lowest in the most deprived urban areas, showing that the widest inequalities in life expectancy across the three settlement types were in urban areas. From the second deprivation quintile, male life expectancy was highest in village and dispersed areas. For this area type, there was a notable difference of 3.4 years between the fourth and fifth (most deprived) quintiles, compared with just 2.3 years between the first (least deprived) and fourth quintile. However, in comparison with urban and town and fringe areas, there was still smaller variation in life expectancy in village and dispersed settlements.

There was a similar trend in life expectancy by settlement type and deprivation quintile in females. Table 2 shows that expectation of life was highest in the least deprived and lowest in the most deprived urban areas, although the latter result was not significant. In quintiles 2 to 5 (most deprived), life expectancy was highest in village and dispersed settlements and lowest in urban areas, although Figure 5 shows that life expectancy in urban and town and fringe areas had a very similar pattern, differing by less than four months within each deprivation quintile. 


\section{Table 2 Period life expectancy at birth by sex and rural/urban settlement type of the RUAC 2004 and IMD 2007 quintile, England, 2001-07}

\begin{tabular}{|c|c|c|c|c|c|c|c|}
\hline Settlement type & IMD 2007 & $\begin{array}{c}\text { Male life } \\
\text { expectancy at } \\
\text { birth }\end{array}$ & $\begin{array}{l}\text { Lower } 95 \% \\
\text { confidence } \\
\text { interval }\end{array}$ & $\begin{array}{l}\text { Upper } 95 \% \\
\text { confidence } \\
\text { interval }\end{array}$ & $\begin{array}{l}\text { Female life } \\
\text { expectancy at } \\
\text { birth }\end{array}$ & $\begin{array}{l}\text { Lower } 95 \% \\
\text { confidence } \\
\text { interval }\end{array}$ & $\begin{array}{l}\text { Upper } 95 \% \\
\text { confidence } \\
\text { interval }\end{array}$ \\
\hline \multirow[t]{5}{*}{ Urban } & Least & 80.3 & 80.3 & 80.4 & 83.6 & 83.5 & 83.6 \\
\hline & 2 & 78.8 & 78.7 & 78.8 & 82.4 & 82.4 & 82.5 \\
\hline & 3 & 77.4 & 77.3 & 77.4 & 81.5 & 81.5 & 81.6 \\
\hline & 4 & 75.4 & 75.4 & 75.5 & 80.2 & 80.2 & 80.3 \\
\hline & Most & 72.3 & 72.3 & 72.4 & 78.1 & 78.1 & 78.2 \\
\hline \multirow[t]{5}{*}{ Town \& fringe } & Least & 79.8 & 79.7 & 79.9 & 83.3 & 83.2 & 83.4 \\
\hline & 2 & 78.4 & 78.2 & 78.5 & 82.5 & 82.4 & 82.6 \\
\hline & 3 & 77.3 & 77.1 & 77.4 & 81.6 & 81.4 & 81.7 \\
\hline & 4 & 75.7 & 75.5 & 75.9 & 80.3 & 80.1 & 80.5 \\
\hline & Most & 73.4 & 73.1 & 73.7 & 78.4 & 78.1 & 78.7 \\
\hline Village \& & Least & 80.0 & 79.9 & 80.2 & 83.2 & 83.0 & 83.3 \\
\hline \multirow[t]{4}{*}{ dispersed } & 2 & 79.3 & 79.2 & 79.4 & 82.7 & 82.6 & 82.8 \\
\hline & 3 & 78.5 & 78.4 & 78.6 & 82.3 & 82.2 & 82.4 \\
\hline & 4 & 77.7 & 77.5 & 78.0 & 81.7 & 81.5 & 81.9 \\
\hline & Most & 74.3 & 73.5 & 75.1 & 78.6 & 77.8 & 79.3 \\
\hline
\end{tabular}




\section{Figure 5}

\section{Period life expectancy at birth by sex and rural/urban settlement type of the RUAC 2004 and IMD 2007 quintile, England, 2001-07}

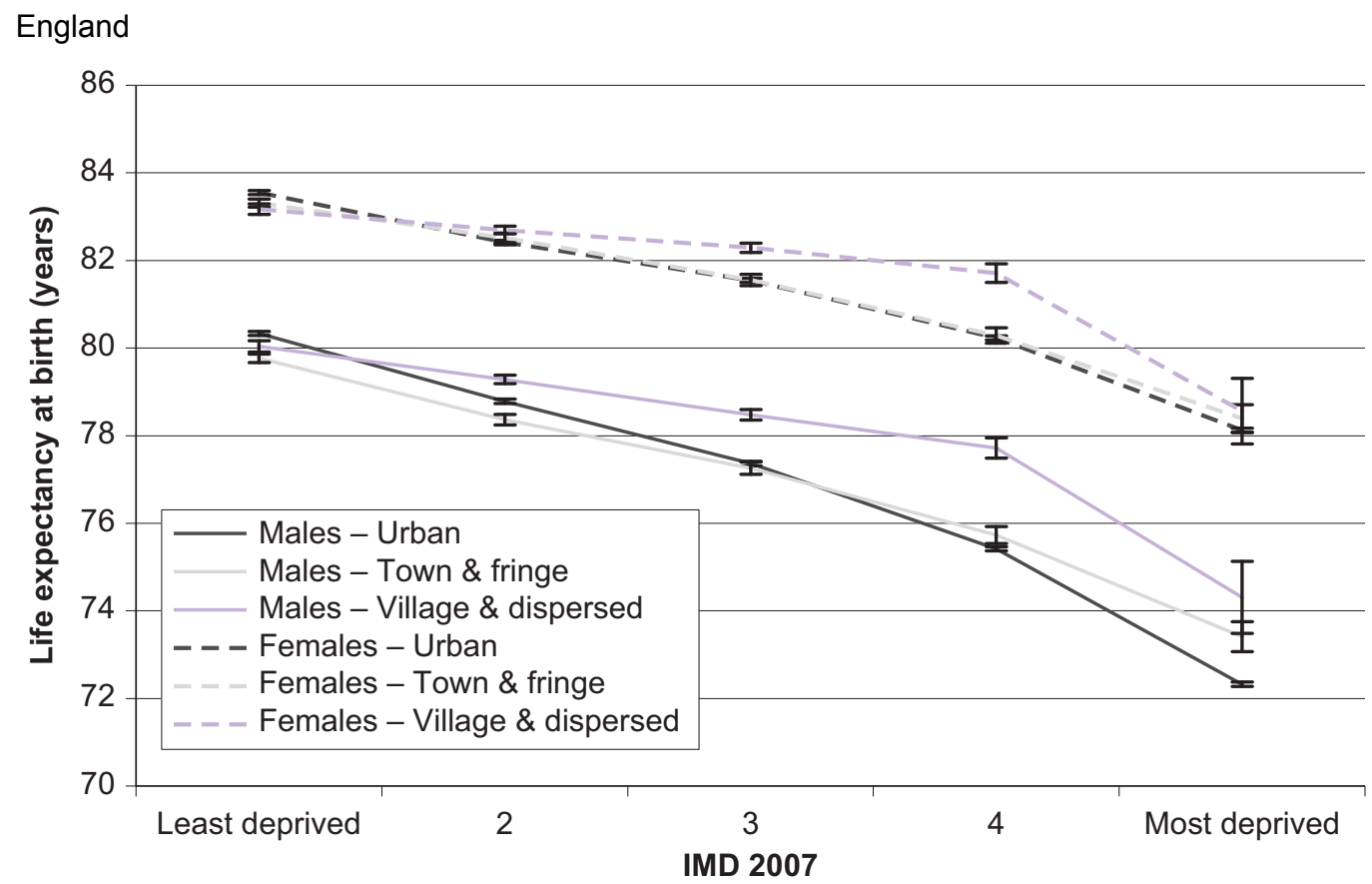

In each settlement type, the differences across the deprivation quintiles were much smaller in females than in males. For females, life expectancy varied by 5.5 years in urban areas, 4.9 years in town and fringe areas, and by 4.6 years in village and dispersed settlements. In males, the differences were 8.0 years, 6.4 years and 5.7 years respectively.

When compared with the England figures, the results for life expectancy across all deprivation quintiles in urban areas are very similar, which may be reflective of the fact that approximately 80 per cent of the population between 2001-07 lived in urban settlements. Although rural areas have fewer residents, variation was evident within different settlement types, with village and dispersed areas experiencing higher life expectancies across the four lowest deprivation quintiles than town and fringe areas. Apart from those in the least deprived quintile, figures for the expectation of life in village and dispersed settlements were above the England average.

\section{Life expectancy in rural and urban sparsity contexts}

For further analysis, the RUAC 2004 was split into four sparsity contexts: urban less sparse/sparse and rural less sparse/sparse. Figure 6 shows that life expectancy was highest in rural less sparse areas for males (78.6 years) and in rural sparse areas for females (82.7 years), although variations between rural areas were small and the confidence intervals for males in rural contexts showed that the differences in life expectancy were not significant. The lowest life expectancies were in urban sparse areas for males (76.1 years) and in urban sparse and less sparse areas for females (81.0 years). For both sexes, life expectancy in each of the rural sparsity contexts was above the England average. However, within both rural and urban areas, sparse areas were not significantly different to less sparse areas. 
Figure 6 Period life expectancy at birth by sex and rural/urban sparsity context of the RUAC 2004, England, 2001-07

England

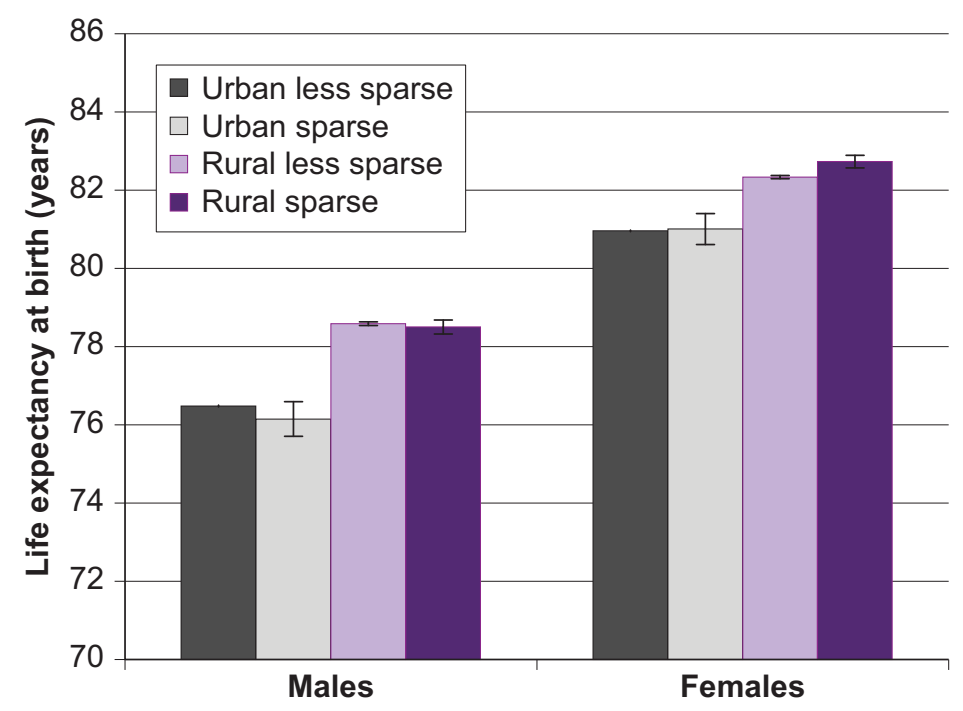

Table 3 shows the life expectancy results for sparsity contexts by deprivation quintile. Results were not calculated for the least deprived urban sparse and the most deprived rural sparse areas due to small populations. The results showed wide variations between the least and most deprived categories. For males, life expectancy was highest in the least deprived urban less sparse areas (80.3 years), although the figure was only 0.4 years higher than life expectancy in the corresponding rural sparse and less sparse areas (79.9 years), and the upper confidence interval in the least deprived rural sparse category was highest at 80.5 years. In contrast, expectation of life was lowest in the most deprived less sparse urban areas (72.3 years). A similar pattern was observed in females, however, the differences between the highest and lowest life expectancies in each sparsity context were smaller. Although not all deprivation quintiles were included in the results, there was less variation in life expectancy in sparse areas than in less sparse areas.

The steepest gradient in life expectancy between the least deprived and most deprived areas was observed in the less sparse urban areas for both males (8.0 years) and females (5.5 years). In men, the differences in other areas ranged by 6.4 years in rural less sparse areas, 6.2 years in urban sparse areas, and 2.1 years in rural sparse areas. The differences were much smaller in women, ranging by 4.9 years, 2.9 years and 1.1 years for the respective areas. However, not all deprivation quintiles were included in these gradients. 
Table $3 \quad$ Period life expectancy at birth by sex and rural/urban sparsity context of the RUAC 2004 and IMD 2007 quintile, England, 2001-07

\begin{tabular}{|c|c|c|c|c|c|c|c|}
\hline Sparsity context & IMD 2007 & $\begin{array}{c}\text { Male life } \\
\text { expectancy at } \\
\text { birth }\end{array}$ & $\begin{array}{c}\text { Lower } 95 \% \\
\text { confidence } \\
\text { interval }\end{array}$ & $\begin{array}{l}\text { Upper } 95 \% \\
\text { confidence } \\
\text { interval }\end{array}$ & $\begin{array}{c}\text { Female life } \\
\text { expectancy at } \\
\text { birth }\end{array}$ & $\begin{array}{l}\text { Lower } 95 \% \\
\text { confidence } \\
\text { interval }\end{array}$ & $\begin{array}{l}\text { Upper } 95 \% \\
\text { confidence } \\
\text { interval }\end{array}$ \\
\hline \multirow[t]{5}{*}{ Urban less sparse } & Least & 80.3 & 80.3 & 80.4 & 83.6 & 83.5 & 83.6 \\
\hline & 2 & 78.8 & 78.7 & 78.8 & 82.4 & 82.4 & 82.5 \\
\hline & 3 & 77.4 & 77.3 & 77.4 & 81.5 & 81.5 & 81.6 \\
\hline & 4 & 75.4 & 75.4 & 75.5 & 80.2 & 80.2 & 80.3 \\
\hline & Most & 72.3 & 72.3 & 72.4 & 78.1 & 78.1 & 78.2 \\
\hline \multirow[t]{5}{*}{ Urban sparse } & Least & & & & & & \\
\hline & 2 & 79.4 & 78.6 & 80.3 & 81.2 & 80.2 & 82.2 \\
\hline & 3 & 77.4 & 76.5 & 78.4 & 82.3 & 81.5 & 83.1 \\
\hline & 4 & 75.6 & 74.8 & 76.3 & 80.9 & 80.3 & 81.5 \\
\hline & Most & 73.2 & 72.1 & 74.3 & 79.4 & 78.5 & 80.3 \\
\hline \multirow[t]{5}{*}{ Rural less sparse } & Least & 79.9 & 79.8 & 80.0 & 83.3 & 83.2 & 83.3 \\
\hline & 2 & 78.9 & 78.8 & 79.0 & 82.6 & 82.5 & 82.7 \\
\hline & 3 & 77.9 & 77.8 & 78.0 & 81.9 & 81.8 & 81.9 \\
\hline & 4 & 76.3 & 76.1 & 76.5 & 80.6 & 80.4 & 80.7 \\
\hline & Most & 73.5 & 73.2 & 73.8 & 78.4 & 78.1 & 78.7 \\
\hline \multirow[t]{4}{*}{ Rural sparse } & Least & 79.9 & 79.2 & 80.5 & 82.8 & 82.1 & 83.5 \\
\hline & 2 & 79.0 & 78.6 & 79.4 & 83.2 & 82.8 & 83.5 \\
\hline & 3 & 78.5 & 78.3 & 78.8 & 82.9 & 82.7 & 83.2 \\
\hline & 4 & 77.8 & 77.4 & 78.2 & 82.1 & 81.8 & 82.5 \\
\hline
\end{tabular}

These categories have small populations and were therefore excluded from the life expectancy calculations.

\section{Discussion}

\section{Summary of main findings}

For the 2001-07 period, life expectancy in England was 76.9 years for males and 81.3 years for females. The inclusion of IMD 2007 deprivation quintiles in the calculations had a large impact on the results, which varied by 7.8 years for men and 5.4 years for women between the least and most deprived quintiles. Males living in the less deprived quintiles had similar life expectancies to females living in the more deprived quintiles in both urban and rural areas.

Overall, life expectancy was higher in rural areas than urban areas for both males and females. When the impact of deprivation within different area types was examined, wide inequalities were 
evident, particularly among men and in urban areas. Although the expectation of life was highest in the least deprived urban areas, it was also lowest in the most deprived urban areas, showing wide disparities within this area type. Deprivation in rural areas had seemingly less effect on the rural life expectancy figures as there was smaller variation between the least and most deprived quintiles.

Within rural settlement types, life expectancy was higher in village and dispersed areas than town and fringe areas. However, in village and dispersed communities, there was a large difference between the fourth and fifth deprivation quintiles, although the confidence intervals in the most deprived quintile were wide. Nonetheless, this shows that there may be pockets of acute deprivation within this settlement type that need to be addressed.

In terms of rural and urban sparsity contexts, the longest life expectancies were in rural less sparse areas for both sexes. Although not all categories could be included in the deprivation analysis, the results still showed broad variations, with life expectancy being highest in the least deprived urban less sparse areas and lowest in the most deprived urban less sparse areas. Patterns of life expectancies within sparse areas were not clear, even though seven years of data were aggregated. The nature of the areas may mask small pockets of deprivation and poor health which are difficult to capture, and this is reflected in the large confidence intervals surrounding figures for this area type.

\section{Comparison to other studies}

The findings of this study were consistent with results and reports from previous research which found that life expectancy is generally higher in rural areas and in less deprived areas, and lower in urban and more deprived areas (Charlton 1996; Gartner et al. 2007; Woods et al. 2005).

Using the OPCS91 area classification (Wallace et al. 1995), Charlton (1997) reported that in 1981 and 1992, life expectancy at birth in England and Wales was lowest in urban areas, particularly in manufacturing and mining areas, while it was highest in the most prosperous, growth and rural areas. Gartner et al. (2007) also found that in Wales for 1999-03, there were more urban wards within the fifth of areas with the lowest life expectancies and more rural wards in the highest fifths. Within rural areas of the RUAC 2004, it was also showed that life expectancy was higher in sparse rural wards compared with less sparse rural wards. However, no clear trend was evident between sparse and less sparse rural areas of England in the current study, even when deprivation was taken into account.

In terms of deprivation, studies which have investigated differences in life expectancy across different types of geographical areas (e.g. government office regions and health authorities) have found greater inequalities between the more deprived areas than between lesser deprived areas, and larger variations between men than women (Woods et al. 2005; Raleigh and Kiri 1997). These findings are consistent with those in the current study.

Over time, some studies report that while improvements have been made, gaps in life expectancy between areas with the highest and lowest results have increased (Charlton 1996; Raleigh and Kiri 1997). ONS sub-national life expectancy figures calculated from 1991-93 to 2006-08 show that it improved in all local authorities over this period, by 4.2 years on average for men and by 2.9 years on average for women (Office for National Statistics 2009b). However, although variations in life 
expectancies between government office regions in England have reduced, differences between local authorities with the highest and lowest life expectancies have widened over this period. Though, when Kensington and Chelsea was excluded from the 2006-08 figures, the differences in the widths of inequality between the two time periods reduced from 2.4 years to 1.0 year for males and from 3.5 years to 0.4 years for females. Due to the availability of LSOA population estimates (from 2001 onwards only) and the number of years for which data needed to be aggregated in the current study, it was not possible to compare time periods. This is highlighted below as a limitation of the analysis.

\section{Limitations of the analysis}

An ecological approach was taken to this study, whereby aggregated data about the population in terms of area and deprivation measures were used to produce life expectancy results, to give an indication of average health outcomes. However, this method is susceptible to the ecological fallacy, which means that assumptions about individuals cannot be made from results relating to aggregate data (Bryman 2008). This limitation is also emphasised by the claim that the poor health of individuals can be masked by favourable averages of the surrounding population (Haynes and Gale 2000).

The use of LSOA-level data in this analysis partly minimises this limitation as LSOAs are based on small, approximately equal population sizes. However, rural LSOAs generally cover a larger geographical area in comparison with urban LSOAs, meaning that urban areas are more likely to be homogeneous and include people with similar characteristics. This may have had some effect on the results and account, in part, for larger inequality gaps in urban areas.

Life expectancy at birth figures are based on the current population and mortality rates of a given area. The results are an estimate of the number of years a person would survive if he or she experienced the area's age-specific mortality rates for the rest of his or her life. The methodology takes no account of migration, which may make a significant difference to the results, particularly as there is a tendency for healthier people to migrate while the less healthy stay at home (O'Reilly et al. 2007). However, this type of analysis would not be possible within the current death registration system in England as it is the area of usual residence of the deceased that is recorded on death certificates, which does not necessarily reflect the area where they spent most of their life.

This study was based on the assumption that area-based classifications and deprivation-based measures are appropriate and accurate to define and distinguish between different areas. However, limitations and associated methodological issues have been raised in previous work (for example Higgs 1999; Romeri et al. 2006). At the individual-level, socio-economic circumstances and health outcomes, even within small areas, may vary greatly and are not necessarily concentrated in, for example, deprived inner city areas or affluent rural settlements. However, the use of small area LSOAs in this analysis is a substantial improvement on previous studies carried out using larger geographical areas.

To improve the current study, the calculation of time series data would enable comparisons to be made over different periods and determine whether inequalities within different area types persist. However, data aggregated over a number of years is required to calculate robust results so further 
analyses may be limited in terms of meaningfulness and timeliness. A further option, which would be feasible to build upon this study, would be to include life expectancy at age 65 results in the analysis, particularly as rural populations tend to be older than urban populations.

Although life expectancy figures are a useful indicator of health outcomes, Higgs (1999) states that 'more research is needed to establish the types of factors that are unique to rural areas that may be impacting on health experience and health status' (1999, p.218).

As part of the wider Defra project into inequalities in health outcomes in rural areas, further studies examining differences in mortality, the relationship between self-perceived health and migration and the influence of socio-economic status, and the association between access to health services and the outcomes of heart attacks (survived or died) have been conducted (Forthcoming).

\section{Conclusion}

This study reports on variations in life expectancy at birth for males and females in England over the 2001-07 period, by RUAC 2004 and IMD 2007 categories. The results established clear inequalities both between and within rural and urban areas. Life expectancy at birth improved with increasing rurality and those born in village and dispersed areas could expect to live longer than those in town and fringe areas. In terms of sparsity contexts, the highest life expectancies were in less sparse rural areas, although perhaps due to their very nature, results were unclear for both rural and urban sparse areas. Urban areas experienced lower life expectancies over the 2001-07 period compared with rural areas (apart from those in the least deprived quintile) and when the impact of deprivation was considered, urban areas had the widest gaps between the highest and lowest figures, particularly in men.

The results of this study reflect those reported in earlier studies, that people living in rural settlements and in the least deprived areas are expected to live longer than those living in urban and in the most deprived areas. They show that it is important to examine differences in life expectancies in both area and deprivation contexts. Within rural areas, there were intricate differences between life expectancies, which are often overlooked when analysing all rural areas together. The results provide useful evidence of health outcomes experienced within rural and urban areas, which may be used to inform future policy. 


\section{References}

Asthana, S., Halliday, J., Brigham, P. and Gibson, A. (2002) Rural deprivation and service need: a review of the literature and an assessment of indicators for rural service planning, South West Public Health Observatory: Bristol

Barnett, S., Roderick, P., Martin, D., Diamond, I. and Wrigley, H. (2002) 'Interrelations between three proxies of health care need at the small area level: an urban/rural comparison', Journal of Epidemiology and Community Health 56 pp 754-761

Bibby, P. and Shepherd, J. (2004) 'Developing a New Classification of Urban and Rural Areas for Policy Purposes - the Methodology', accessed 10 March 2010, available on the Department for Environment, Food and Rural Affairs website as 'Rural Urban Methodology Report' at: http://www.defra.gov.uk/evidence/statistics/rural/rural-definition.html

Bryman, A. (2008) Social Research Methods (Third Edition), Oxford: Oxford University Press

Carstairs, V. and Morris, R. (1989) 'Deprivation and mortality: an alternative to social class?' Community Medicine 11 pp 210-219

Charlton, J. (1996) 'Which areas are healthiest?', Population Trends 83 pp 17-24

Chiang, C. L. (1968) 'The life table and its construction' in Chiang C L (Ed) Introduction to Stochastic Processes in Biostatistics, John Wiley \& Sons: New York

Commission for Rural Communities (2008) State of the Countryside 2008, accessed 10 March 2010, available on the Commission for Rural Communities website at: http://www.ruralcommunities.gov.uk/projects/stateofthecountryside2008/overview

Communities and Local Government (2008) The English Indices of Deprivation 2007, Communities and Local Government: London

The Countryside Agency, Department for Environment, Food and Rural Affairs, Office of the Deputy Prime Minister, Office for National Statistics, Welsh Assembly Government (2004) Rural and Urban Area Classification 2004: An Introductory Guide, accessed 10 March 2010, available on the Office for National Statistics website at: http://www.statistics.gov.uk/geography/downloads/Rural Urban Introductory Guidev2.pdf

Gartner, A., Gibbon, R. and Riley, M. (2007) A profile of rural health in Wales, Wales Centre for Health: Cardiff

Gartner, A., Farewell, D., Dunstan, F. and Gordon, E. (2008) 'Differences in mortality between rural and urban areas in England and Wales, 2002-04', Health Statistics Quarterly 39 pp 6-13

Gilthorpe, M.S. and Wilson, R.C. (2003) 'Rural/urban differences in the association between deprivation and healthcare utilisation', Social Science \& Medicine 57 pp 2055-2063 
Government Actuary's Department (online a) 'Interim Life Tables Methodology', accessed 10 March 2010, available on the Government Actuary's Department website at:

http://www.gad.gov.uk/Demography\%20Data/Life\%20Tables/Interim life tables methodology.html

Government Actuary's Department (online b) 'Interim Life Tables Notation', accessed 10 March 2010, available on the Government Actuary's Department website at:

http://www.gad.gov.uk/Demography\%20Data/Life\%20Tables/Interim life tables notation.html

Haynes, R. and Gale, S. (2000) 'Deprivation and poor health in rural areas: inequalities hidden by averages', Health and Place 6 pp 275-285

Higgs, G. (1999) 'Investigating trends in rural health outcomes: a research agenda', Geoforum 30 pp 203-221

Huff, N., Macleod, C., Ebdon, D., Phillips, D., Davies, L. and Nicholson, A. (1999) 'Inequalities in mortality and illness in Trent NHS Region', Journal of Public Health Medicine, 21(1) pp 81-87

Jarman, B. (1983) 'Identification of under-privileged areas', British Medical Journal, 286 pp 705709

Jordan, H., Roderick, P. and Martin, D. (2004) 'The Index of Multiple Deprivation 2000 and accessibility effects on health', Journal of Epidemiology and Community Health 58 pp 250-257

Joseph Rowntree Foundation (2000) Exclusive countryside? Social inclusion and regeneration in rural areas, Joseph Rowntree Foundation: York

Kyte, L. and Gordon, E. (2009) 'Life expectancy at birth and at age 65 by local areas in the United Kingdom, 2006-08', Health Statistics Quarterly 44 pp 59-68

Martin, D., Brigham, P., Roderick, P., Barnett, S., Diamond, I. (2000) 'The (mis)representation of rural deprivation', Environment and Planning A 32 pp 735-751

Newell, C. (1994) Methods and Models in Demography, John Wiley \& Sons: Chichester

Office for National Statistics (2005) 'Life table templates', accessed 10 March 2010, available on the Office for National Statistics website at:

http://www.statistics.gov.uk/statbase/ssdataset.asp?vlnk=6949

Office for National Statistics (2009a) 'News Release: Life expectancy at birth remains highest in South of England', accessed 10 March 2010, available on the Office for National Statistics website at: http://www.statistics.gov.uk/StatBase/Product.asp?vlnk=8841

Office for National Statistics (2009b) 'Life expectancy at birth and at age 65 by local areas in the United Kingdom', accessed 10 March 2010, available on the Office for National Statistics website at: $\underline{\text { http://www.statistics.gov.uk/StatBase/Product.asp?vlnk=8841 }}$

O'Reilly, G., O’Reilly, D., Rosato, M. and Connolly, S. (2007) 'Urban and rural variations in morbidity and mortality in Northern Ireland', BMC Public Health 7:123 
Raleigh, V. S. and Kiri, V. A. (1997) 'Life expectancy in England: variations and trends by gender, health authority, and level of deprivation', Journal of Epidemiology and Community Health $51 \mathrm{pp}$ 649-658

Romeri, E., Baker, A. and Griffiths, C. (2006) 'Mortality by deprivation and cause of death in England and Wales, 1999-2003', Health Statistics Quarterly 32 pp 19-34

Shyrock, H. S. and Siegel, J. S. (1976) The Methods and Materials of Demography (abridged edition), Academic Press: New York

Toson, B. and Baker, A. (2003) 'Life expectancy at birth: methodological options for small populations', National Statistics Methodological Series No.33, accessed 10 March 2010, available on the Office for National Statistics website at:

http://www.statistics.gov.uk/statbase/Product.asp?vlnk=10626

Townsend, P., Phillimore, P., Beattie, A. (1988) Health and Deprivation: Inequality and the North, Bristol: Croom Helm

Wallace, M., Charlton, J. and Denham, C. (1995) 'The new OPCS area classifications', Population Trends 79 pp 15-30

Woods, L. M., Rachet, B., Riga, M., Stone, N., Shah, A. and Coleman, M. P. (2005) 'Geographical variation in life expectancy at birth in England and Wales is largely explained by deprivation', Journal of Epidemiology and Community Health 59 pp 115-120 